\title{
Designing and Evaluating Sustainable Logistics Networks
}

\section{J. Quariguasi Frota Neto, J.M. Bloemhof-Ruwaard, J.A.E.E. van Nunen and H.W.G.M. van Heck}

\begin{tabular}{|l|l|}
\hline \multicolumn{2}{|l|}{ ERIM REPORT SERIES RESEARCH IN MANAGEMENT } \\
\hline ERIM Report Series reference number & ERS-2006-003-LIS \\
\hline Publication & January 2006 \\
\hline Number of pages & 28 \\
\hline Persistent paper URL & \\
\hline Email address corresponding author & jquariguasi@rsm.nl \\
\hline Address & Erasmus Research Institute of Management (ERIM) \\
& RSM Erasmus University / Erasmus School of Economics \\
& Erasmus Universiteit Rotterdam \\
& P.O.Box 1738 \\
& 3000 DR Rotterdam, The Netherlands \\
& Phone: + 31 10408 1182 \\
& Fax: + 31 104089640 \\
& Email: info@erim.eur.nl \\
& Internet: www.erim.eur.nl \\
\hline
\end{tabular}

Bibliographic data and classifications of all the ERIM reports are also available on the ERIM website: www.erim.eur.nl 


\section{ERASMUS RESEARCH INSTITUTE OF MANAGEMENT}

\section{REPORT SERIES \\ RESEARCH IN MANAGEMENT}

\begin{tabular}{|l|l|}
\hline \multicolumn{2}{|l|}{ ABSTRACT AND KEYWORDS } \\
\hline Abstract & $\begin{array}{l}\text { The objective in this paper is to shed light into the design of logistic networks balancing profit } \\
\text { and the environment. More specifically we intend to i) determine the main factors influencing } \\
\text { environmental performance and costs in logistic networks ii) present a comprehensive } \\
\text { framework and mathematical formulation, based on multiobjective programming, integrating all } \\
\text { relevant variables in order to explore efficient logistic network configurations iii) present the } \\
\text { expected computational results of such formulation and iv) introduce a technique to evaluate the } \\
\text { efficiency of existing logistic networks.The European Pulp and Paper Industry will be used to } \\
\text { illustrate our findings. }\end{array}$ \\
\hline Free Keywords & $\begin{array}{l}\text { Supply Chain Design, Sustainable Supply Chain, Eco-efficiency, Multi-Objective Programming } \\
\text { (MOP), Data Envelopment Analysis (DEA). }\end{array}$ \\
\hline Availability & $\begin{array}{l}\text { The ERIM Report Series is distributed through the following platforms: } \\
\text { Academic Repository at Erasmus University (DEAR), DEAR ERIM Series Portal } \\
\text { Social Science Research Network (SSRN), SSRN ERIM Series Webpage } \\
\text { Research Papers in Economics (REPEC), REPEC ERIM Series Webpage }\end{array}$ \\
\hline Classifications & $\begin{array}{l}\text { The electronic versions of the papers in the ERIM report Series contain bibliographic metadata } \\
\text { by the following classification systems: } \\
\text { Library of Congress Classification, (LCC) } \underline{\text { LCC Webpage }} \\
\text { Journal of Economic Literature, (JEL), JEL Webpage } \\
\text { ACM Computing Classification System CCS Webpage } \\
\text { Inspec Classification scheme (ICS), ICS Webpage }\end{array}$ \\
\hline
\end{tabular}




\title{
Designing and Evaluating Sustainable Logistics Networks
}

\author{
J. Quariguasi Frota Neto *, J.M. Bloemhof-Ruwaard, \\ J.A.E.E. van Nunen, H.W.G.M. van Heck \\ Rotterdam School of Management (RSM), Erasmus University, The Netherlands \\ January 13,2006
}

\begin{abstract}
The objective in this paper is to shed light into the design of logistic networks balancing profit and the environment. More specifically we intend to i) determine the main factors influencing environmental performance and costs in logistic networks ii) present a comprehensive framework and mathematical formulation, based on multiobjective programming, integrating all relevant variables in order to explore efficient logistic network configurations iii) present the expected computational results of such formulation and iv) introduce a technique to evaluate the efficiency of existing logistic networks.The European Pulp and Paper Industry will be used to illustrate our findings.
\end{abstract}

Keywords: Supply Chain Design, Sustainable Supply Chain, Eco-efficiency, Multi-Objective Programming (MOP), Data Envelopment Analysis (DEA).

*corresponding author. Tel 31(0)10 408-1781. E-mail: jquariguasi@rsm.nl 


\section{Introduction}

In recent years, consumers and governments have been pressing companies to reduce the environmental impact of their products and processes (Thierry et al. [1995]). For reactive companies, the main drivers into a more sustainable existence are legislation and negative consumer response. Legislation was the main ecological driver in business from roughly 1970 to 1985 (Weaver et al. [1997] quoting Fisher and Schot [1993]) and is still changing the way companies operate. The European Community (EU), for instance, adopted in the last years several mandatory recycling policies in order to persuade companies to act in a more ecological friendly way. The European directive for the Waste of Electrical and Electronic Equipment (WEEE) is an example. The members of European Community have committed themselves to develop and implement legislation that makes producers responsible for the collection, treatment, recycling and environmentally safe disposal of all electrical and electronic equipment. Thirteen out of the twenty-five EU members have already sanctioned WEEE-style legislation. Consumers have also became both more aware and educated about environmental issues. First, because of the increasing exposure of environment related topics, such as acid rain, green house effect and desertification. Second because of the appearance of eco-certificates, which help these consumers to identify eco-friendly products.

A number of companies have pro-actively acted in favor of a more sustainable development. Among those, a group also perceived the economical potential of environmental friendly logistic networks. IBM, for instance, has programs to receive end-of-use products, promote second hand items internet auctions and dismantle equipment as a source of spare parts (Fleischmann et al. [2003]). HP has programs to upgrade obsolete machines, to recover end-of-life products, and to help the donation of used equipment to charity institutions. BMW remanufactures and resells components, such as engines and water pump engines (Ayres et al. [1997]).

Although these initiatives from IBM, HP and BMW, proved to be profitable and environmental friendly, they are exceptions. Substantial improvement in the environment is 
often only possible with substantial investments bringing none or negative financial returns (Walley and Whitehead [1994]). The goal of improvements in economic activities, including Logistic Networks, is now smartly compromising costs with negative environmental impacts.

In section two we very briefly discuss the advantages of adopting environmental friendly networks, the possible extra associated costs, and the need to smartly compromise the environmental impacts and costs. In section three we present the main variables affecting logistic networks efficiency in terms of the environment and costs. We also present a framework for such networks and a non-articulated multi-objective model. Non-articulated models are those in which the user or Decision Maker do not interact with the model in order to find most preferable solutions. For more information on non-articulated models see Climaco et al. [1996]. A short discussion on computational results for such formulation is also carried out. In section four we provide a simple tool to evaluate Pareto Efficiency, using Data Envelopment Analysis (DEA) techniques and Multi-Objective Programming (MOP). In section six we present an illustrative example of the European Pulp and Paper Sector. Section seven brings the main conclusions.

\section{Environmental Impact and Costs in Logistic Net- works}

The adoption of environmentally friendly logistic networks can bring several benefits to companies. The association of greenness from a certain product, for instance, is a positive differential among environmentally conscious consumers. Green certifications, such as the well known "Flower", promoted by the European Union are initiatives which add value for green products. Furthermore, in industrialized countries, consumers usually boycott products they consider harmful to the planet. MPG, a British product developmentconsultancy, surveyed in 1989 American customers and found that more than half of them refused buying products that may harm the environment (Cairncross [1992]). Products 
derived from the unsustainable use of tropical forests,for instance, also suffer rejection by consumers in industrialized nations (Schimidheiny [1998]).

At a sector level, environmental friendly logistic networks may avoid costly mandatory adjustments. This cames from the fact that governments are more keen to approve legal restrictions to logistic network (recycling quotas, for instance) in sectors that are not proactively working in reducing their environmental impacts. Furthermore, companies may have to preserve the environment for the simple reason that their existence is intrinsically related to a sustainable exploration of certain natural resources. The pulp and paper industry, for instance, will exist in the future due to a rational exploration of its forests.

The full exploration of more environmentally friendly solutions in Logistic Networks is, however, bounded by the increase in costs. In closed-loop supply chains, for instance, the process of recycling and shredding is nowadays preferred to cleaner solutions, such as com-

plete or partial (spare parts) re-using, because for most cases disassembly costs overcome the prices of new raw material. Furthermore, whenever the producers are not responsible for their end-of-use products, and recovery value is low, land filling will often be the final destination of such products.

Companies and government should be aware of the trade-offs between business and economy and the environment. It is essential, therefore, to search for solutions that smartly compromise these two dimensions.

\section{Pareto Efficiency in Logistic Networks in terms of the environment and costs}

In a Logistic Network, a number of actors will influence efficiency in terms of costs and the environment. Suppliers, manufactures, consumers, logistic operators and third parties operating in testing, refurbishing, recycling and energy production for the end-of-life products are the main players. These actors perform the majority of the activities impacting business and the environment. 
In general terms, the activities performed in a logistic network are related to manufacturing, transportation, use and end-of-life products' destination. Figure 1 pictures them. The decisions regarding these activities will, therefore, determine the network costs and environment impact. These decisions are strategic (e.g. location of factories), tactical (e.g. products end-of-life destination) as well as operational (e.g. choosing suppliers, 3th parties in collection, refurbishing, etc)

Furthermore, it is clear that choosing the right factors in modelling specific problems is

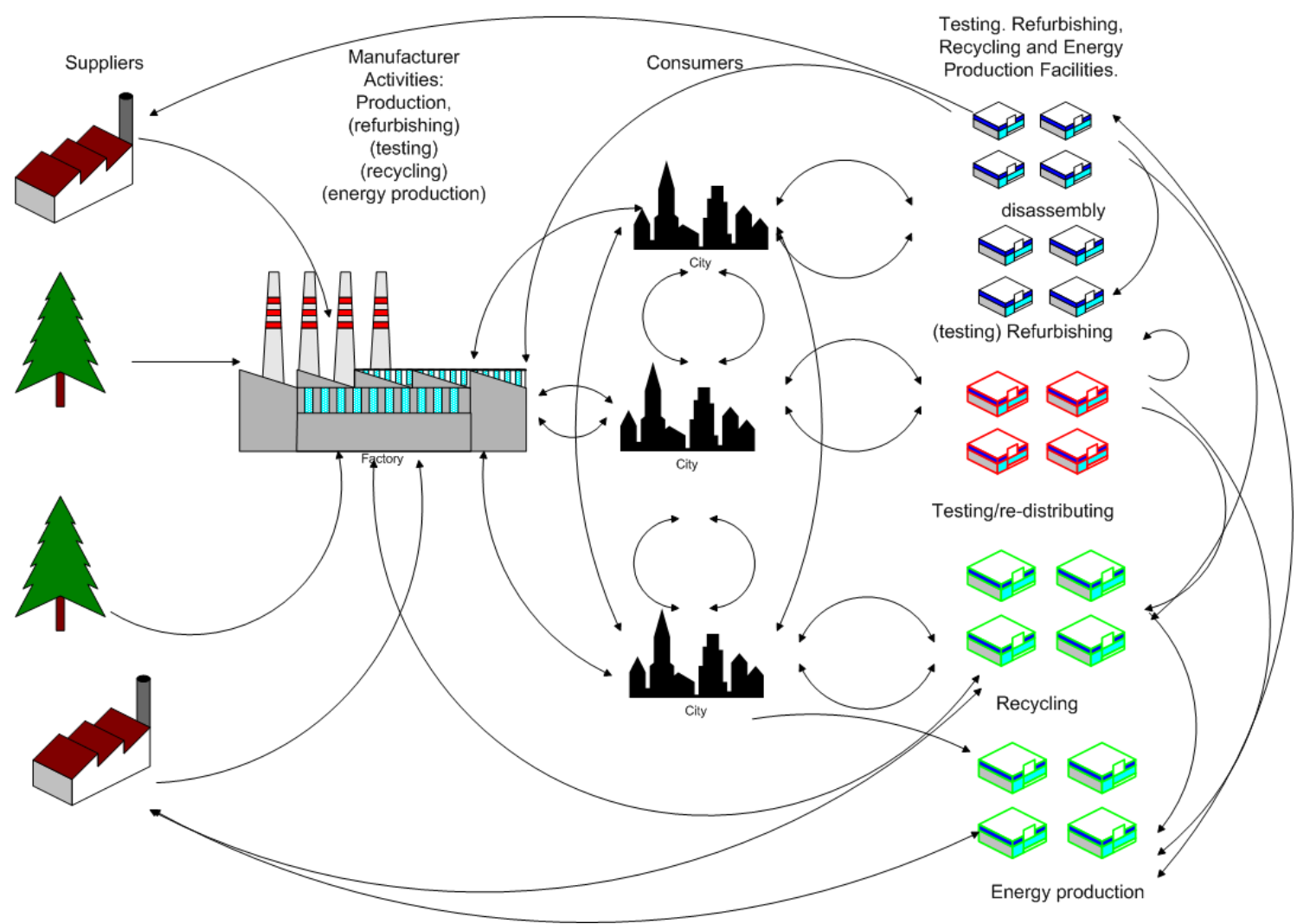

Figure 1: Sustainable Logistic Network

crucial. The combinatorial and multi-objective nature of such problems requires, besides smart algorithms, conceptual models that keep the problem tractable in terms of computational complexity, without losing its explanatory power. In problems with low inverse flows (e.g. the reverse logistic of cameras), for instance, the model can exclude the decision 
regarding the location of manufacturing plants, and leave the location problem to the endof-use facilities (Fleischmann [2000]). Table 1 shows, in broad terms, the main activities influencing the environmental impact and costs in Logistic Networks. Literature in logis-

\begin{tabular}{|c|c|}
\hline Type of Factor & Variables \\
\hline 1.Transportation & $\begin{array}{l}\text { 1.1. Transport from supplier to manufacturer and vice-versa } \\
\text { 1.2. Transport from supplier to consumers and vice-versa } \\
\text { 1.3. Transport from supplier to end-of-life facilities and vice-versa } \\
\text { 1.3. Transport from manufacturers to consumers and vice-versa } \\
\text { 1.4. Transport from manufacturers to end-of-life facilities and vice-versa } \\
\text { 1.4. Transport from consumers to end-of-life facilities and vice-versa }\end{array}$ \\
\hline 2.Manufacturing & $\begin{array}{l}\text { 2.1. Manufacturing at Suppliers } \\
\text { 2.2. Manufacturing at Manufacturers }\end{array}$ \\
\hline 3.Product Use & 3.1. Product use by consumers \\
\hline 3.Testing & 4.1. Testing \\
\hline 5.End-of-use Alternatives & $\begin{array}{c}\text { 5.1. Re-use } \\
\text { 5.2. Refurbishing } \\
\text { 5.3. Recycling } \\
\text { 5.4. Energy Production }\end{array}$ \\
\hline
\end{tabular}

Table 1: Main Activities Influencing Costs and Environmental Impact in Logistic Networks

tic network design is mostly divided in two approaches: minimizing costs or maximizing profits and minimizing environmental impact. There is little done integrating these two formulations (see Bloemhof-Ruwaard et al. [2004]). The drawback of such perspectives is straightforward: it's not possible to look for solutions compromising both objectives. We propose the optimization of both objectives simultaneously, in order to make it possible for the Decision Maker (DM), in logistic networks with centralized decision makers (monopoly), to evaluate his choice and select, out of a number of solutions provided by the model, the one that best compromises his objectives in terms of the environment and cost. Another important application is the definition of upper bounds for networks with multiple agents. The utility of such bound is threefold:

1. Evaluation of the current situation in terms of the system's efficiency relative to environmental impact and costs. It is possible, for instance, to calculate efficiency 
indices for existing network configurations using Data Envelopment Analysis Techniques. (for further description of DEA see Chanes et al. [1978]) .

2. Determination of the trade-offs between the resulting environmental impact and costs in a logistic network. This allows an easy visualization and straightforward interpretation between the trade-offs.

3. Evaluation of the necessity of legislation and, if so, to assess the efficiency of different types.We also prove general rules for these different legislations, using the concept of Pareto optimality.

The idea of exploring the best alternatives is based on Pareto Optimality. The Pareto optimal frontier is composed by the set of the images of all efficient solutions of the network in relation to two objectives: optimize economical and environmental goals (e.g. cost minimization and waste minimization, respectively). A multi-objective programming is denoted by (Steuer and Piercy [2005]):

$$
\max \left\{c^{1} x=z_{1}\right\} \ldots \max \left\{c^{k} x=z_{k}\right\} \text { s.t. }\left\{x \in R^{n} \mid A x \leq b, b \in R^{m}, x \geq 0\right\}
$$

where $\mathrm{k}$ is the number of objectives. A point $\hat{x} \in S \subset R^{n}$ is efficient if and only if there is no $x \in S$ such that $c^{i} x \geq c^{i} \hat{x}$ and there is at least one $c^{i} x<c^{i} \hat{x}$. The efficient set or efficient frontier is the set of all efficient solutions.

In our formulation, $c^{1} x$ represents the environmental impact of a certain solution, and $c^{2} x$ the respective total cost $(\mathrm{k}=2)$. The coefficients of the first objective function are obtained via Life Cycle Analysis (LCA), a standard technique for evaluating environmental impact. The objective is to explore, completely or not, the set of efficient logistic network configurations. In other words, we are interested in supply chains in which it's not possible to decrease costs or environmental impacts without a trade-off between them. Figure 2 illustrates the efficient frontier. The Pareto frontier can be completely defined by a set of all extreme points in a MOP in formulation with two objectives. Although determining these points is the only task to be performed to obtain the frontier, its accomplishment 


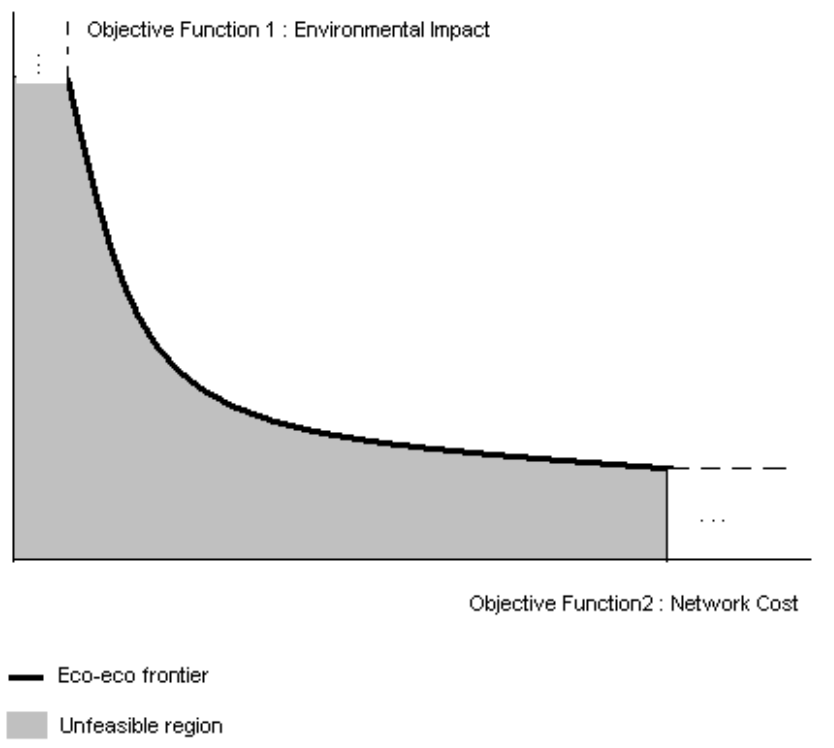

Figure 2: Pareto Optimal Frontier

is extremely CPU-time consuming. The complete exploration of all extreme efficient solutions for large networks is mathematically intractable (for CPU-time processing details see Steuer [1994] and Steuer and Piercy [2005]), even for linear allocation models. For integer (location-allocation) models computational efforts are even bigger, as expected.

In order to obtain a subset of efficient network configurations, it is possible to formulate the MOP, for the linear case, as several problems with a single objective. The principle of such heuristics is to rationally explore different weights for the Objective Functions, avoiding weight indifference regions. Despite the term 'heuristic' the final subset is composed by optimal solutions, only. We apply this term to designate a non-comprehensive exploration of the subset analyzed. The cardinality of this subset is defined by model parameters, but is obviously upper bounded by the number of non-dominated solutions in a MOP formulation. An estimation for the latter can be found in Steuer and Piercy [2005]. Equation 2 
gives the equivalent LP of equation (1), for problems with two objective functions:

$$
\min \left\{c^{1} x \lambda_{1}+c^{2} x\left(1-\lambda_{1}\right)\right\} \text { s.t. }\left\{x \in R^{n} \mid A x \leq b, b \in R^{m}, x \geq 0\right\}
$$

For mixed-linear and integer problems (e.g. decision regarding disassembly, locationallocation) not only the frontiers has to be defined heuristically, but also the points defining it. It is easy to see that, in case the single objective problem is NP-complete, the multiobjective will never be $\mathrm{P}$, in case $N P \neq P$. For a comprehensive description of heuristics in Multi-objective problems see Jones et al. [2002]. For multi-objective combinatorial problems, Ehrgott [2000] and Ehrgott and Gandibleux [2000] present a detailed review. A survey on multi-objective meta-heuristics is available in Jones et al. [2002], Hansen [1998] and Espejo and Galvao [2004].

\section{Evaluating Pareto Efficiency in Logistic Networks}

Intuitively, we can think of the efficient solutions explored in the last section as benchmarks for existing logistic networks. Mapping environmental impact and costs of the current configuration, and comparing to the theoretical optimal, gives us an idea of how (in)efficient is the existing logistic network. In case we find that actual environmental impact and costs are close to the frontier, for instance, there will be no need for configuration changes, for centralized decision networks, or intervention (e.g. legislation) for networks with multiple agents.

Furthermore, it is possible to give a measure of efficiency for existing networks. In order to do so, we have to need the following lemmas:

Lemma 1 Each image of a non-dominated $\hat{x}$ solution in (1) $\left(\left[c^{1} \hat{x} \lambda_{1}, \ldots, c^{1} \hat{x} \lambda_{n}\right]\right)$ is an effcient Decision Making Unit (DMU) in a Data Envelopment Analysis problem with DMU's $\left(\left[c^{1} x \lambda_{1}, \ldots, c^{1} x \lambda_{n}\right]\right)$ for $x \in S \subset R^{n}$ in (1)

Proof: For a continuous structure set of solutions, we have that all elements of this set have an associated weight in the single objective linear formulation. It implies that every 

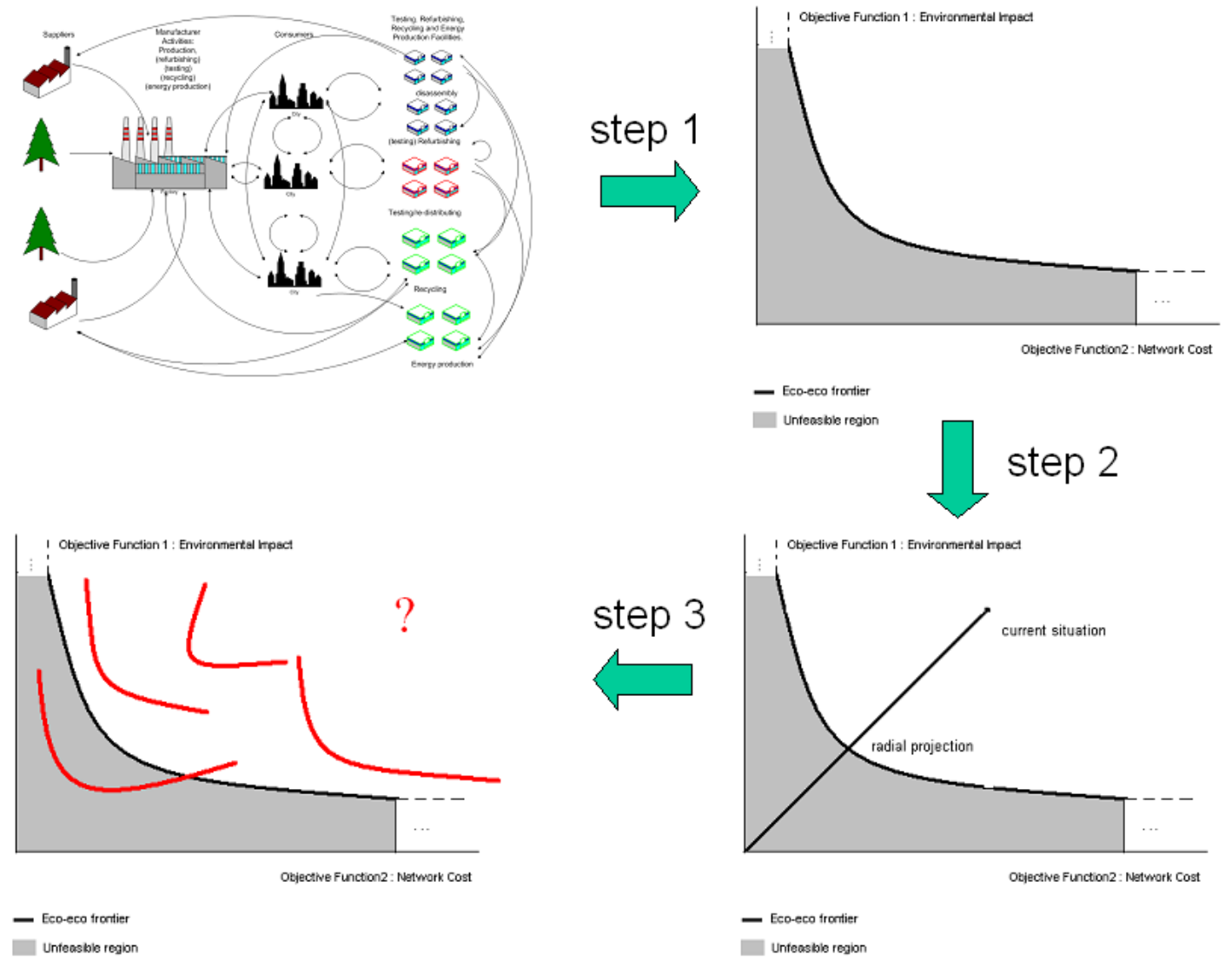

Figure 3: Steps to calculate efficiency

solution belongs to the convex hull of the efficient solution set (Espejo and Galvao [2004] citing Bitran [1977]). It implies that the efficient solutions will map efficient DMUs in a DEA problem, once they belong to the convex hull, and therefore can not be outside the efficient frontier.

Lemma 2 Not every image of a non-dominated $\hat{x}$ solution in (1) $\left(\left[c^{1} \hat{x} \lambda_{1}, \ldots, c^{1} \hat{x} \lambda_{n}\right]\right)$ is an efficient Decision Making Unit (DMU) in a Data Envelopment Analysis problem with $D M U^{\prime} s\left(\left[c^{1} x \lambda_{1}, \ldots, c^{1} x \lambda_{n}\right]\right)$ for $x \in S \subset R^{n}$ in (1), in case we require $x \in S \subset Z^{n}$ Proof: Non-supported solutions (for more details see Bitran [1977]) in 0-1 and integer problems are counter examples. 
For an in-depth discussion of such commonalities of DEA and MOP, see Korhonen et al. [2003] and Estellita Lins [2004]. We first formalize our approach, for linear models (allocation models) and then extend for mix-integer ones.

We map every image of the non-dominated solutions as an efficient DMU of a DEA formulation, using Lemma 1. Once the problem is linear, all efficient solutions are supported, and are, therefore, efficient in DEA terms (the same does not hold with combinatorial or mixed-integer problems). After this step, we calculate efficiency based on the radial projection efficiency measure first proposed by Chanes et al. [1978]. It is also possible to explore non-radial projections for such problems, allowing the decision maker to more freely explore the efficient frontier. For interactive and non-articulated methods for finding radial projections see Quariguasi Frota Neto [2005], Halme et al. [1999], Thanassoulis and Dyson [1992] and Zhu [1996]. Furthermore, it is easy to see that every non-radial projection in the DEA formulation maps a real solution in the original logistic network. For mixed-integer problems, the set of unsupported efficient solutions are not efficient in a DEA perspective, as proved in Lemma 2. It is worth to note, though, that this problem can be easily solved considering an non-convex subset of feasible solutions in the DEA formulation, or excluding the non-supported solutions. Figure 3 illustrates the process. The optimization and evaluation of the Logistic Networks can be summarize in the following steps:

1. Explore, partially or completely, non-dominated solutions of the Logistic Network. In case of complete exploration of linear models, a convex piecewise linear frontier can be constructed. For integer models, the frontier is likely to be no longer convex and can not be explored via standard DEA techniques. The convex combinations also do not correspond to real networks, but are still valid for efficiency analysis purposes. In case of non-exhaustive exploration of the efficient solutions, the frontier is an upper bound of the real one, and its closeness with the real theoretical frontier will depend on the number of non dominated vertexes explored.

2. Calculate the efficiency of the Logistic Network. The current situation is bounded by the efficient frontier and will be a convex combination of the efficient points or an 
inefficient DMU in DEA terms. It is possible, furthermore, to evaluate the efficiency of the current situation through standard DEA techniques for end-of-use decisions and allocation problems, as well as non-standard techniques for end-of-use decisions and location-allocation problems.

3. Access the efficiency of a mandatory legislation by its capacity of locking-out environmental harmful solutions without deteriorating the proposed frontier and evaluate the impact of market based legislation. In some cases, it may be possible to improve the efficient frontier, giving cheaper and more environmental friendly solutions, as well as locking out harmful environmental logistic network configurations, through adequate market based legislation.

In the next section we illustrate the use of the proposed methodology to optimize the logistic networks in terms of the environment and costs, as well as the efficiency of the current one, and to illustrate the impact of mandatory legislation.

\section{Example: The European Paper and Pulp Sector}

In order to illustrate the concepts presented in the last sections we take the European pulp and paper industry as a study case. The sector has significant impact in both environment and business for the European Union. For Scandinavian countries, for instance, it responds for a significant part of the industrial activity and generates a considerable parcel of the GDP. In Finland, the forest sector represents $7 \%$ of the GDP and approximately a fifth of industrial production (Federation [2005]). For the environment, the impacts appear in different parts of the life cycle: forest management, pulp production, pulp bleaching, paper consumption, waste management and transportation (Bloemhof-Ruwaard et al. [1996]). The magnitude of waste paper produced is impressive: in Europe, it responds for $35 \%$ of the total waste by volume (Bloemhof-Ruwaard et al. [1996] apud Buwal [1991]). 


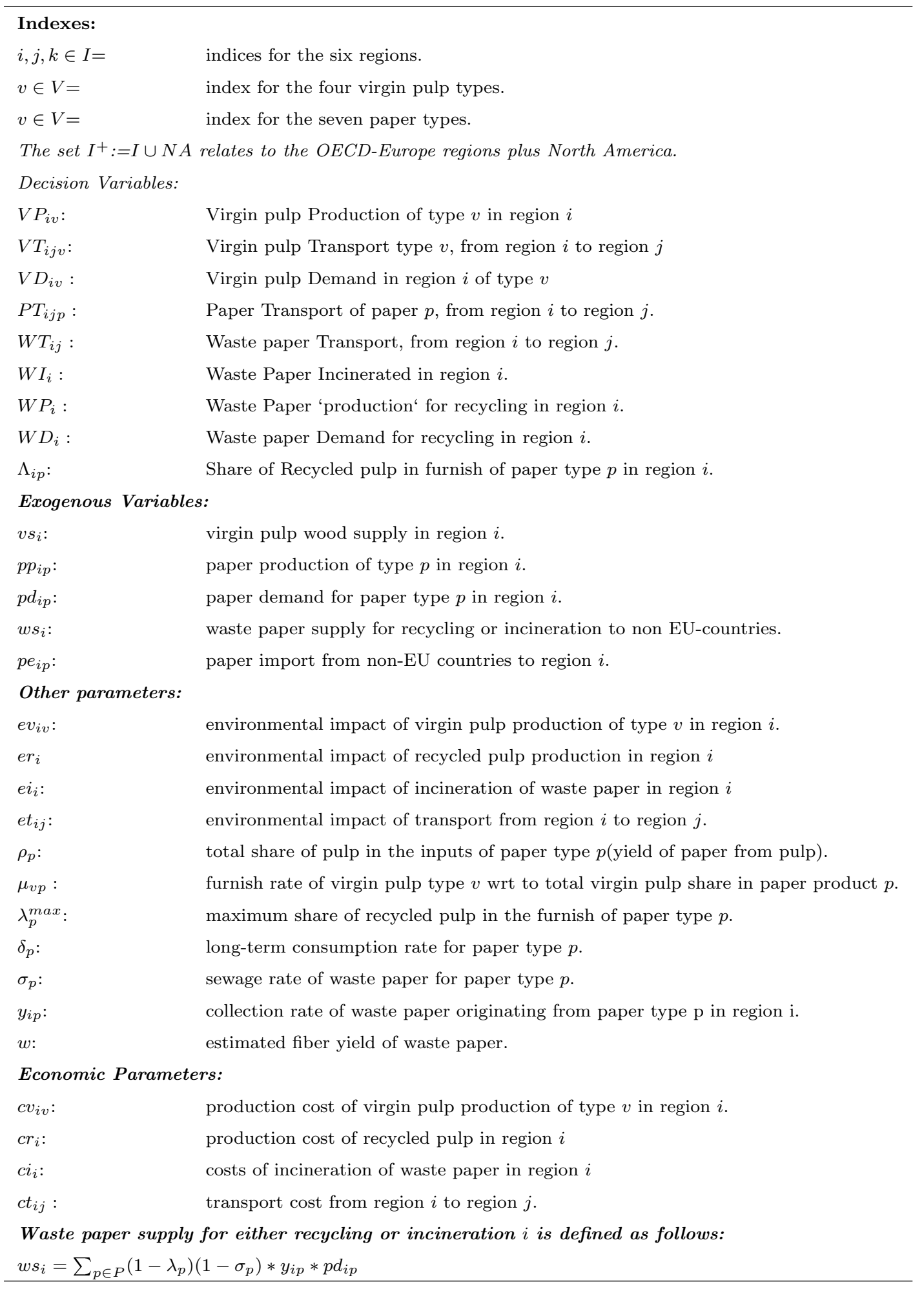

Table 2: Variables For the European Pulp and Paper Model 
We describe the problem as a multi-objective linear problem, with the network cost and environmental impact objectives to be optimized. We consider facility locations as fixed, which lead us to a problem of allocation and end-of-use decision. This formulation can be easily extended to include facility allocation decisions. For an operational perspective, though, it is reasonable to assume that the location of energy generation plants, paper recycling or paper production will not change in a short period of time. The model divides

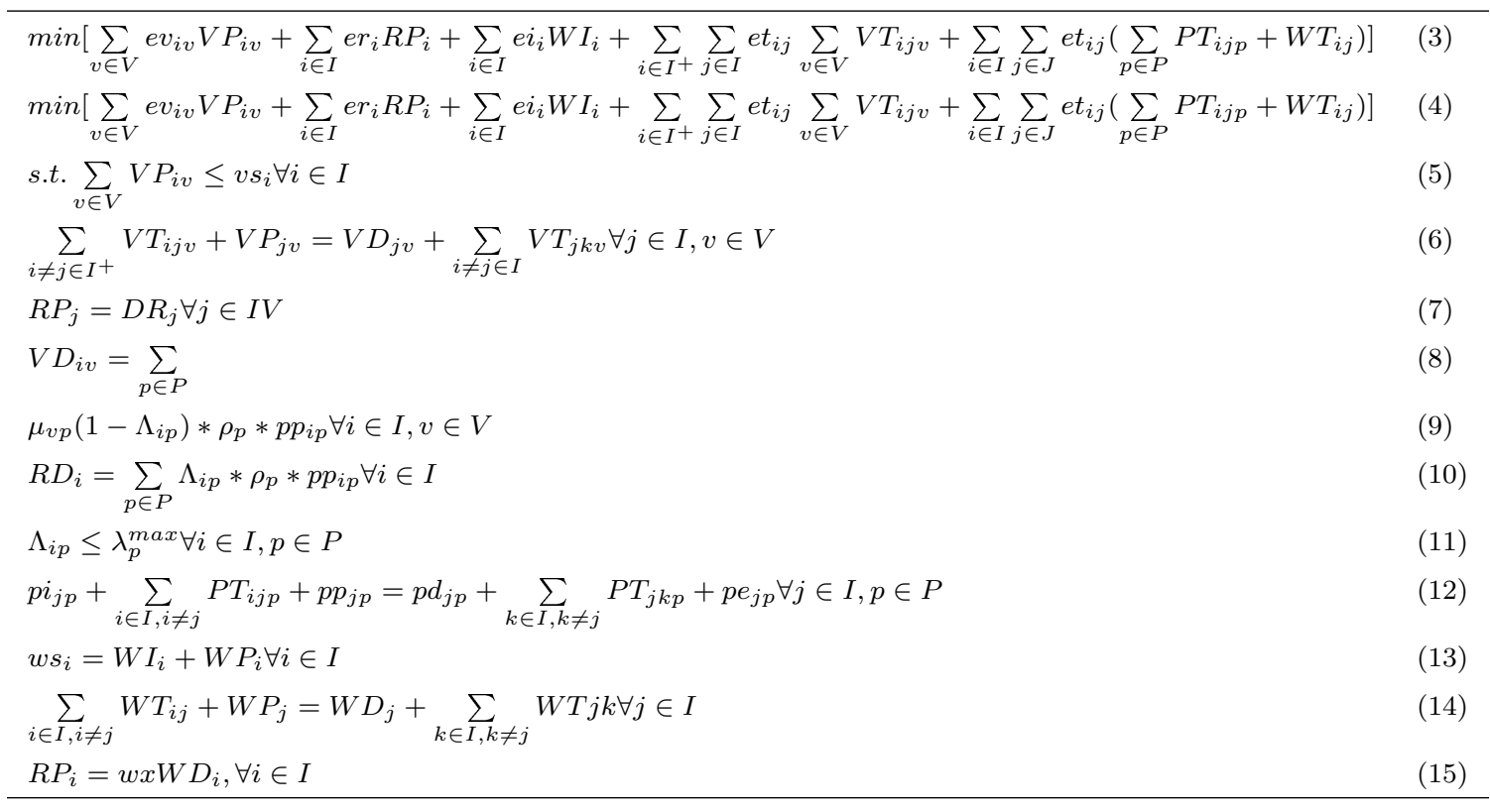

Table 3: Mathematical formulation for the European Pulp and Paper Model

the EU in six regions: Scandinavia (Finland and Sweden), France, UK, Italy and Iberia (Portugal and Spain). These six regions are responsible for $80 \%$ of the paper consumption and production in the European Union. In order to assess ecological impact we use the environmental index proposed by Bloemhof-Ruwaard et al. [1996]. The index uses Life Cycle Analysis, considering the diverse emissions in the supply Chain, namely global warming, human toxicity, ecotoxicity, photochemical oxidation, acidification, nitrification and solid waste, and provides a single weighted measure for environmental impact for each phase of the supply chain. The economical objective function is the sum of the cost of the following activities: transportation, production, recycling and incineration. The environmental 
impact is also calculated from these activities.

The logistic network we describe has multiple agents: producers, consumers, $3^{\text {th }}$ parts working on recycling, incineration and energy generation. In a higher level, governments can also be considered players, for their role in legislation. We model the system, though, in a single agent perspective. This approach allows us to explore the efficient frontier, and from that, as presented in section 2

1. Provide an upper bound for a system in a game theoretical perspective. The modelling of environmental legislation is an example of application for a bi-level game: the government creates legislation with the objective to diminish environmental impact, without severely harming the economy, and companies adapt to such legislation, at most cases trying to minimize the associated extra costs. For the European Governments, for example, it will provide insights on the best alternatives for the used paper. Nowadays, such decisions are highly biased by economical interest of the members, as well as by the belief that some alternatives are environmentally friendly preferred. Scandinavia, for instance, advocates that the production of clean virgin pulp is both environmental and economically preferable over recycling. France favors incineration, meanwhile Germany goes for recycling (Bloemhof-Ruwaard et al. [1996]). An example of applications of Game Theory in Legislation is found in Amouzegar and Moshirvaziri [1999].

2. Determine the cost of decreasing environmental impact for the paper and pulp sector. This is key information for Decision Makers in the private and public sectors. For governments, this information is useful as an input for decisions regarding subsidizing or taxing activities (e.g. incineration,transport,recycling) of the Logistic Network, for instance. In case the trade-offs are generous in terms of environment, read good improvements with low costs, it is a good alternative to subsidize clean logistic networks. In case it is too costly to decrease environmental impact, better to tax such 
activities and invest and other sectors with better trade-offs.

3. Determine the efficiency of the sector relative to environment and costs. The efficiency will tell us how much the system can be improved with initiatives integrating and directing the players at the logistic network. This re-design of the Logistic Network can happen directly, by a self re-organization of the players (in that case, considering cooperative players), as well as indirectly via an leader, from a game theoretical perspective. In that case, governments will take the hole of leader, projecting the actual inefficient system to the frontier via legislation.

4. Determine 'optimal' configurations for the European Paper and Pulp Sector. The results provide a clear guideline for the configurations of production, transport and end-of-use destination for paper.

Objective (3) minimizes environmental impact of virgin pulp (both in Europe and North America), recycled pulp production, waste paper incineration, and transport. Objective (4) minimize the costs for the same activities. Constraints (5) are the capacity constrains for wood pulp. Constraints (6) and (7) define flow conditions for virgin pulp and recycled pulp. Constraints (8) define the allowable share of recycled pulp in order to satisfy conditions for paper types. Constraints (9) define the allowable share of recycled pulp in order to satisfy conditions for paper types. Constraints (10) represent the natural bound on the share of recycled pulp in the overall furnish of paper products. Constraints (11)define flow condition for paper. Constraints (12) define the destination of collected waste paper to be either incineration or recycling. Constraints (13) define flow conditions for waste paper. Constraints (14) consider the yield from waste paper for recycled pulp. Constraints (4) and (6), allow us to represent all papers produced in one variable. Constraint (7) uses the same rationale to reduce the number of technologies used for virgin pulp processing. Figure 4 represents the network flow for one European region.

For the Paper and Pulp sector we assume that: 
1. The production and consumption of paper is constant. This implies that the virgin and recycling pulp demand, as well as the waste generation are maintained in the actual levels.

2. The production of virgin pulp making is limited by the capacity installed in each region. Furthermore, the formulation does not allow increment in capacity.

3. The proportion of paper produced (newsprint $14 \%$, printing quality paper $36 \%$, liner $12 \%$, fluting $9 \%$, boxboard $9 \%$, holsehold $5 \%$ and others $15 \%$ ) is fixed.

4. The proportion of virgin pulp production technology (sulphate bleach, sulphate unbleach, sulphite bleach and TMP bleach ) used is fixed.

5. The proportion between the actual use of recycled fiber and its maximum value is equal for each paper. The bigger the maximum of recycled pulp allowed (this is a technical restriction. Papers such as printing accept a maximum of $50 \%$ recycling pulp), the bigger the proportion in relation to the overall recycled pulp used.

6. The network flow conditions involving virgin and recycled pulp, paper and waste should be respected. Furthermore, we also consider that there is no transport of recycled pulp.

The decision variables for the problem are therefore: the transportation of virgin pulp, paper and waste paper among the six described regions the import and export of, respectively, pulp and paper from outside EU and the destination ( incineration or recycling) of the end-of-use paper. The variables are described in Table 1, and the mathematical formulation in Table 3.

We understand that the problem is more complex than is portrayed in the paper, but as said, assumptions presented can be easily relaxed (actually some of those are, in BloemhofRuwaard et al. [1996]). The reason for such simplicity is that we are more interested in showing an application of the proposed methodology than provide results for decision 


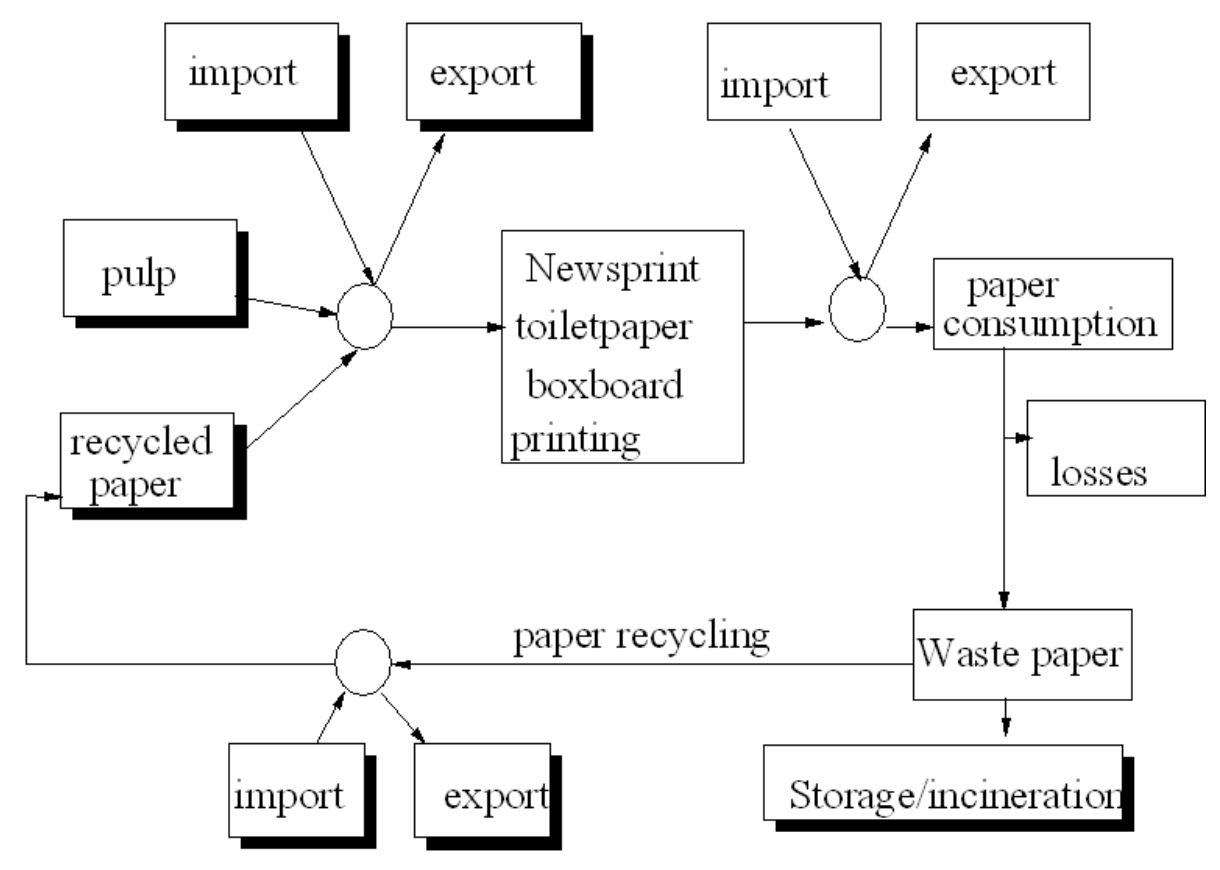

Figure 4: network flow model

making in such industry. We believe that the illustrative model works properly for that purpose.

\section{$6 \quad$ Results}

We first analyze the efficient frontier for the European paper and pulp sector in order to determine the theoretical trade-offs between environmental impact and costs, as described in section 3. Furthermore, we use the frontier to find a measure of efficiency for the actual logistic network, as described in section 4 .

The minimization of environmental impact gives a total cost of approximately $16 \%$ bigger than the configuration with minimal costs. The environmental impact is reduced in $17 \%$, compared to the same value for economical optimization. Note that the objective function values ,in percentage terms, do not differ much among the efficient solutions. The reason is that transportation, which highly impact both costs and environmental impact, is simultaneously optimized for both objectives. 
Another interesting results is that the right side of the frontier, which maps the costly solutions, is dominated by virgin pulp production associated with incineration. Despite the common belief that recycling is always cleaner, solutions with high recycling proportions are not more environmental friendly for the particular case of the European paper and pulp sector. This result is resonant with those found in Bloemhof-Ruwaard et al. [1996]. Recycling is, although, highly present in the lower costs configurations. Mandatory recycling quotas, therefore, may bring no positive results for the environment. 

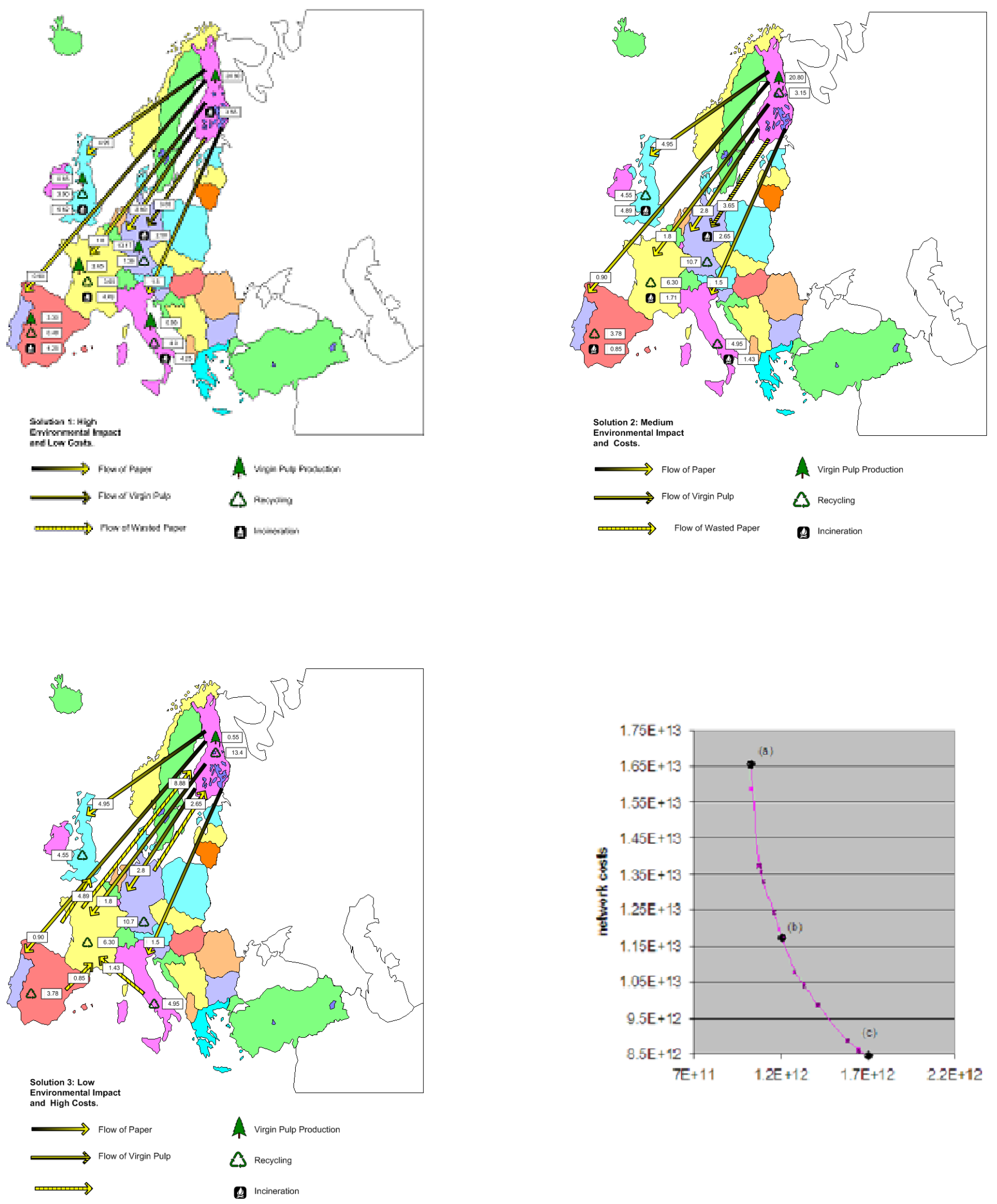

Figure 5: Flow and end-of-life decision for the European Paper and Pulp 
Figures 5 shows three efficient configurations for the European paper and pulp sector, and their respective environmental impact and costs. Note that, although they do not differ much in terms of the environment and cost results, they present quite different configurations. The solution with lowest costs has no incineration, and significant flows of wasted paper, besides the expected flow of new paper from the Scandinavian countries to the rest of Europe. The solution with highest cost is a mix between virgin pulp utilization, incineration and recycling. Also, there is no flow of wasted paper. An intermediate solution presents both incineration and recycling, but no flow of wasted paper. There are also flows of paper from Scandinavia to the rest of Europe and Virgin Pulp to Germany.

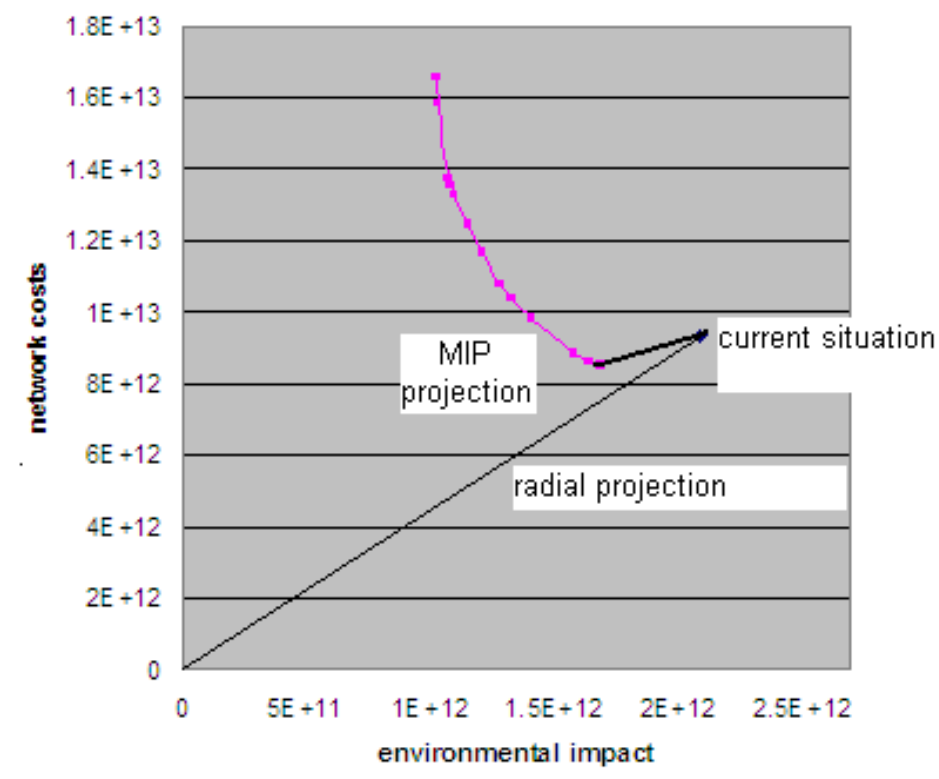

Figure 6: Pareto-optimal frontier for the Pulp and Paper Industry with MIP and radial projections 


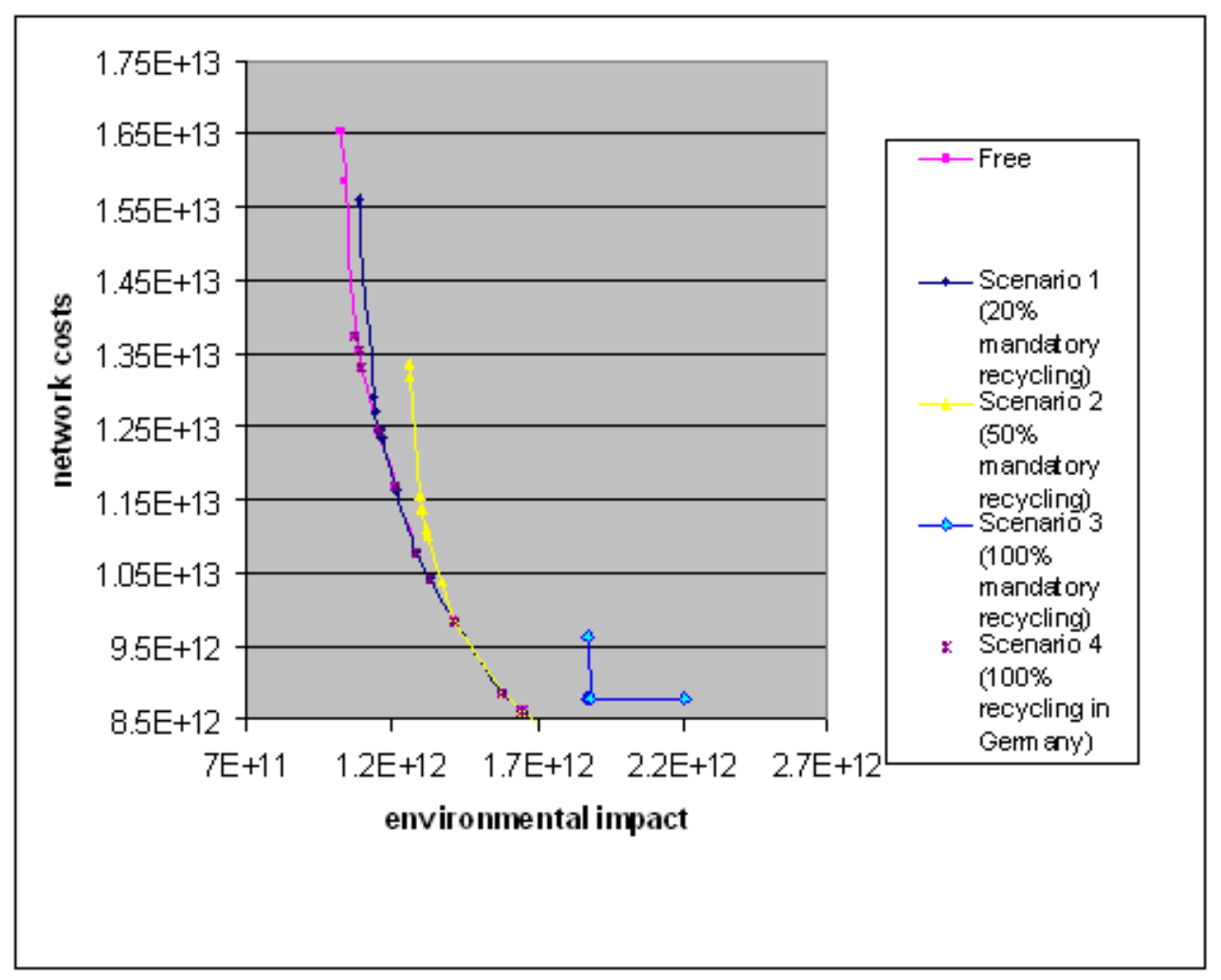

Figure 7: Pareto-optimal frontier for the Pulp and Paper Industry with Mandatory Legislation

In order to calculate the network efficiency, we use the Measure of inefficiency proportions (MIP) proposed in Cooper et al. [1999]. The actual data for 1999's European pulp and paper sector is presented in figure 6. (Bloemhof-Ruwaard et al. [1996]). The Logistic Network measure of inefficiency is equal to 0.24 , which mean that an average of $24 \%$ improvement in the environmental impact and costs in the Logistic Network would be necessary to reach efficiency. Note that we do not use radial projection, despite the easier interpretation of results, due to the risk of projecting in inefficient parts of the frontier. This is a well know problem in literature, and occurs for the data of this specific study case. Furthermore, the MIP model gives a single real number as efficiency measure and incorporate all inefficiencies in the model.In figure 6 the thicker line represents the MIP projection. The efficiency calculation and the optimization phase, are modelled as linear 
systems, and therefore performed in Polynomial time. CPU-time is negligible for both problems.

We also analyze the impact of legislation on the efficient frontier. We explore five scenarios: The first scenario is the $20 \%$ mandatory recycling for all members of the European Union. Here we suppose that the parliament decides to, based on the actual directives for wasted paper, mandate this percentage of recycled pulp. We expand our analysis for $50 \%$ and $100 \%$. We also analyze the result of mandatory legislation in Germany.

The Pareto Optimal configuration, including the scenarios, is presented in figure 7 . Note that recycling mandatory policies may deteriorate the Pareto optimal frontier. It is also worth to highlight that in the case analyzed, it particularly locks out environmentally friendly solutions, instead of the expected effect to lock out unfriendly ones.

The adoption of mandatory legislation for $20 \%$ of recycled pulp does not deteriorate the Pareto-Efficient frontier, but locks-out environmental friendly alternatives. The effect of $50 \%$ use of recycled pulp in European Union and 100\% in Germany is similar: lockingout environmental friendly alternatives and deteriorate the Pareto frontier. Legislation imposing 100\% recycling fiber has the same effect, but with a bigger magnitude.

\section{Conclusions}

The concern of consumers, companies and governments with the environment has steadily increased in the last years. Cleaner process, re-use of products and components, remanufacturing and recycling are example of initiatives to reduce environmental impact in Logistic Networks. Unfortunately, win-win solutions for the environment and business are very elusive in practice.

The adoption of cleaner solutions is generally bounded by an increase in costs. Companies aiming to decrease the environmental impact of their logistic networks should, then, look for good trade-offs between environmental impact and costs. The game is, therefore, smartly compromising the two P's: Planet and Profit. The same rationale is true for governments: effective legislation should take into consideration specific trade-offs of the 
logistic network in question, as well as the efficiency of the existing logistic network.

In this paper we determine the main family of activities influencing the environment and costs in Logistic Network, namely: transportation, manufacturing, product use, testing and end-of-use alternatives. Furthermore, we present a framework for optimizing the design of efficient Logistic Networks, based on multi-objective programming, in terms of the environment and costs. We also discuss the mathematical properties of the efficient frontier for linear, mixed-linear and integer formulations. Applications and further developments of such frontier are also discussed.

In addition, we introduce a new methodology to evaluate efficiency in Logistic Networks, based on the common properties shared by Multi-Objective Programming and Data Envelopment Analysis. We also pinpoint the main mathematical characteristics of such an efficiency indicator. This indicator tells the decision maker, in companies, sectors or governments, about the necessity of better coordinating his logistic networks, or better tuning environmental legislation.

We use the European Pulp and Paper sector as a background for presenting the methodologies proposed in the previous sections. We present the efficient frontier for such sector, as well as the trade-offs between the environment and costs. Furthermore, we show that mandatory legislation favoring recycling will not lock out bad environmental solutions, and will deteriorate the efficiency of the sector in terms of the environment and business. We also show that the actual system have lots of space for win-win gains, via the re-organization of its logistic network, pointing to the adoption of Market Based Legislation. 


\section{References}

M. A. Amouzegar and K. Moshirvaziri. Determining optimal pollution control policies: An application of bilevel programming. European Journal of Operational Research, 119(1): 100-120, 1999.

R. Ayres, G. Ferrer, and T. van Leynseele. Eco-efficiency, asset recovery and remanufacturing. European Management Journal, 15(5), 1997.

G.W. Bitran. Linear multiple objective program with zero-one variables. Mathematical Programming, 13(121-139), 1977.

J. M. Bloemhof-Ruwaard, L. N. VanWassenhove, H. L. Gabel, and P. M. Weaver. Environmental life cycle optimization model for the european pulp and paper industry. Omega-International Journal of Management Science, 24(6):615-629, 1996.

J.M. Bloemhof-Ruwaard, Krikk, H., and Van Wassenhove L.N. OR models for eco-eco closed-loop supply chain optimization., volume 1 of Reverse Logistics: Quantitative Models for Closed-Loop Supply Chains. Springer-Verlag, Berlin/Heiderberg, 1 edition, 2004.

Buwal. Ecobalance of packing materials, state of 1990. Technical report, Swiss Federal Office of Environment, Forests and Landscape (BUWAL), 1991.

F. Cairncross. Costing the Earth: The Challenge for Governments, The Opportunities for Business. Harvard Business School Press, Boston,Massachusetts, 1992.

A. Chanes, W. Cooper, and E. Rhodes. Measuring the efficiency of decision making units. European Journal of Operational Research, 2(6):429444, 1978.

J. Climaco, C.H. Aantunes, and M.J.G Alves. Programao multiobjetivo:mtodos interactivos, "software" e aplicaes. Technical report, Faculdade de Economia da Universidade de Coimbra e INESC., 1996. 
W. W. Cooper, K. S. Park, and J. T. Pastor. Ram: A range adjusted measure of inefficiency for use with additive models, and relations to other models and measures in dea. Journal of Productivity Analysis, 11(1):5-42, 1999.

M. Ehrgott. Multicriteria Optimization. Springer Verlag, Berlin, 2000.

M. Ehrgott and X. Gandibleux. An annoted bibliography on multiobjective combinatorial optimization. Technical report, Report in Wirtschaftsmathematik, 2000.

L.G.A. Espejo and R.D. Galvao. Uma aproximao da fronteira eficiente para um problema de localizao hiersquico de mxima cobertura. Pesquisa Operacional, 24(2), 2004.

Angulo-Meza A C Moreira da Silva Estellita Lins, M.E. A multi-objective approach to determine alternative targets in data envelopment analysis. Journal of Operations Research Society, 55, 2004.

Finish Forest Industries Federation, 2005.

K. Fisher and J. Schot, editors. Environmental Strategies for Industry:International Perspectives on Research Needs and Policy Implications. Island Press, Washington,D.C., 1993.

M. Fleischmann. Quantitative Models for Reverse Logistics. PhD thesis, Erasmus University, 2000.

M. Fleischmann, J.A.E.E. van Nunen, and B. Grave. Integrating closed-loop supply chains and spare-parts management at ibm. Interfaces, 33(6):44-56, 2003.

M. Halme, T. Joro, P. Korhonen, S. Salo, and J. Wallenius. A value efficiency approach to incorporating preference information in data envelopment analysis. Management Science, 45(1):103-115, 1999.

M.P. Hansen. Metaheuristics for multiple objective combinatorial optimization,working paper,. Technical report, Technical University of Denmark,Denmark, 1998. 
D. F. Jones, S. K. Mirrazavi, and M. Tamiz. Multi-objective meta-heuristics: An overview of the current state-of-the-art. European Journal of Operational Research, 137(1):1-9, 2002.

P. Korhonen, S. Stenfors, and M. Syrjanen. Multiple objective approach as an alternative to radial projection in dea. Journal of Productivity Analysis, 20(3):305-321, 2003.

J. Quariguasi Frota Neto. Alternative targets for data envelopment analysis through multiobjetcive linear programming: Rio de janeiro odontological public health system case study. Journal of Operations Research Society, 2005.

S. Schimidheiny. Changing Course: A Global Business Perspective on Develoment and the Environment. MIT Press, 1998.

R. E. Steuer and C. A. Piercy. A regression study of the number of efficient extreme points in multiple objective linear programming. European Journal of Operational Research, 162(2):484-496, 2005.

R.E. Steuer. Random problem generation and the computation of efficient extreme points in multiple objective linear programming. Computational Optimization and Applications, 3:333-347, 1994.

E. Thanassoulis and R. G. Dyson. Estimating preferred target input output levels using data envelopment analysis. European Journal of Operational Research, 56(1):80-97, 1992.

M. Thierry, M. Salomon, J. Vannunen, and L. Vanwassenhove. Strategic issues in product recovery management. California Management Review, 37(2):114-135, 1995.

N. Walley and B. Whitehead. Its not easy being green. Harvard Business Review, 72(3): 46, 1994. 
P.M. Weaver, H.L. Gabel, J. Bloemhof-Ruwaard, and L.N.V. Wassenhove. Optimizing environmental product life cycles. Environmental and Resource Economics, 9:199-224, 1997.

J. Zhu. Data envelopment analysis with preference structure. Journal of the Operational Research Society, 47(1):136-150, 1996. 


\section{Publications in the Report Series Research* in Management}

\section{ERIM Research Program: "Business Processes, Logistics and Information Systems"}

2006

Smart Business Networks Design and Business Genetics

L-F Pau

ERS-2006-002-LIS

Designing and Evaluating Sustainable Logistics Networks

J. Quariguasi Frota Neto, J.M. Bloemhof-Ruwaard, J.A.E.E. van Nunen and H.W.G.M. van Heck ERS-2006-003-LIS

Design and Control of Warehouse Order Picking: a literature review

René de Koster, Tho Le-Duc and Kees Jan Roodbergen

ERS-2006-005-LIS

A Theoretical Analysis of Cooperative Behavior in Multi-agent Q-learning

Ludo Waltman and Uzay Kaymak

ERS-2006-006-LIS

Supply-Chain Culture Clashes in Europe. Pitfalls in Japanese Service Operations

M.B.M. de Koster and M. Shinohara

ERS-2006-007-LIS

* A complete overview of the ERIM Report Series Research in Management: https://ep.eur.nl/handle/1765/1

ERIM Research Programs:

LIS Business Processes, Logistics and Information Systems

ORG Organizing for Performance

MKT Marketing

F\&A Finance and Accounting

STR Strategy and Entrepreneurship 